\title{
Feasibility and cost of FH cascade screening in Belgium (BEL-CASCADE) including a novel rapid rule-out strategy
}

\author{
Olivier S. Descamps ${ }^{\mathrm{a}, \mathrm{b}}$. Ernst Rietzschel ${ }^{\mathrm{c}}$, Anja Laporte $^{\mathrm{d}} \quad$ CIan Buysschaert $^{\mathrm{e}} \quad$,Herbert De Raedt ${ }^{\mathrm{f}}$, \\ Ivan Elegeert $^{\mathrm{g}}$ O Fabien Chenot ${ }^{\mathrm{h}} \quad$ OJean-Philippe Lengele ${ }^{\mathrm{i}} \quad$,Stephane Carlier ${ }^{\mathrm{j}}$ \\ Philippe Vanderheeren $^{\mathrm{k}}$, Fabienne Lienart ${ }^{1}$ (D)Ain Friart ${ }^{\mathrm{m}}$ (DMichel Guillaume ${ }^{\mathrm{n}}$ \\ Hans Vandekerckhove ${ }^{\mathrm{o}}$, Gunther Maudens ${ }^{\mathrm{o}}$ (ID) Ann Mertens ${ }^{\mathrm{p}}$, Philippe van de Borne ${ }^{\mathrm{q}}$, Antoine Bondue ${ }^{\mathrm{q}}$ \\ and Johan De Sutter ${ }^{\mathrm{r}}$
}

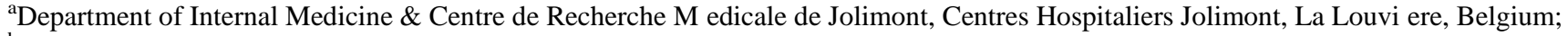
${ }^{\mathrm{b}}$ Department of Cardiology, Cliniques Universitaires Saint-Luc, Brussels, Belgium; ${ }^{\mathrm{c} D e p a r t m e n t ~ o f ~ C a r d i o l o g y, ~ U n i v e r s i t y ~ H o s p i t a l ~}$ Ghent and Ghent University, Ghent, Belgium; ${ }^{\mathrm{d}}$ SANOFI, Brussels, Belgium; ${ }^{\mathrm{e}}$ Department of Cardiology, Algemeen Stedelijk Ziekenhuis, Aalst, Belgium; ' ${ }^{\mathrm{f}}$ Department of Cardiology, Onze-Lieve-Vrouw Ziekenhuis, Aalst, Belgium; ${ }^{\mathrm{g}}$ Department of Cardiology, Algemeen Ziekenhuis Groeninge, Kortrijk, Belgium; ${ }^{\mathrm{h}}$ Department of Cardiology, Grand Hopital de Charleroi, Charleroi, Belgium; ${ }^{\mathrm{i} D e p a r t m e n t}$ of Nephrology, Grand Hopital de Charleroi, Charleroi, Belgium; ${ }^{\mathrm{j} D e p a r t m e n t}$ of Cardiology, CHU Ambroise Par e, Mons, Belgium; ${ }^{\mathrm{k}}$ Department of Cardiology, Sint-Andriesziekenhuis, Tielt, Belgium; ${ }^{1}$ Department of Internal Medicine, CHU Tivoli, La Louvi ere,

Belgium; ' ${ }^{\mathrm{m}}$ Department of Cardiology, CHU Tivoli, La Louvi ere, Belgium; ${ }^{\mathrm{n}}$ Department of Cardiology, CHU de Charleroi, Charleroi, Belgium; ${ }^{\circ}$ Department of Cardiology, Algemeen Ziekenhuis Sint-Lucas, Gent, Belgium; ${ }^{\mathrm{P} D e p a r t m e n t}$ of Endocrinology, University

Hospitals Leuven, Belgium; ' Department of Cardiology, Hopital Erasme, Universit e Libre de Bruxelles, Brussels, Belgium;

${ }^{\mathrm{r}}$ Department of Cardiology, Algemeen Ziekenhuis Maria Middelares, Gent, Belgium
\end{abstract}

ABSTRACT

Background: Familial hypercholesterolaemia (FH) is underdiagnosed in most countries. We report our first experience from a national pilot project of cascade screening in relatives of FH patients. Methodology: Participating specialists recruited consecutive index patients (IP) with Dutch Lipid Clinic Network (DLCN) score 6. After informed consent, the relatives were visited by the nurses to collect relevant clinical data and perform blood sampling for lipid profile measurement. FH diagnosis in the relatives was based on the DLCN and/or MEDPED FH (Make-Early-Diagnosis-toPrevent-Early-Deaths-in-FH) criteria.

Results: In a period of 18 months, a total of 127 IP (90 with definite FH and 37 with probable

FH) were enrolled in 15 centres. Out of the 270 relatives visited by the nurses, 105 were sus- pected of having FH: 31 with DCLN score >8, 33 with DLCN score 5-8 and 41 with MEDPED $\mathrm{FH}$

criteria. In a post-hoc analysis, another set of MEDPED FH criteria established in the Netherlands and adapted to Belgium allowed to detect $\mathrm{FH}$ in 51 additional relatives.

Conclusion: In a country with no national FH screening program, our pilot project demonstrated that implementing a simple phenotypical FH cascade screening strategy using the collaboration of motivated specialists and two nurses, allowed to diagnose $\mathrm{FH}$ in 127 index patients and an additional 105 of their relatives over the two-year period. Newly developed MEDPED FH cut-offs, easily applicable by a nurse with a single blood sample, might further improve the sensitivity of detecting FH within families.
ARTICLE HISTORY

Received 19 June 2020

Revised 31 August 2020

Accepted 2 September 2020

KEYWORDS

Familial hypercholesterolaemia; genetics;

cardiovascular prevention; cascade screening;

familial history; heredity

\section{Introduction}

Familial hypercholesterolaemia (FH) is currently underdiagnosed and undertreated in many countries [1]. However, FH fulfils the necessary prerequisite conditions for a an effective screening strategy: (i) it is detectable at an early stage by clinical or genetic tests, (ii) these tests are acceptable both physically and psychologically, (iii) FH testing benefits outweigh the cost, and (iv) FH treatment at an early stage is more benefi- cial than at a later stage. The current practice by General Practitioners (GPs), based on the traditional individual patient/physician contact has several pitfalls including the low rate of screening amongst family members. A good alternative to the traditional approach is "cascade screening". This strategy has been applied with success in the Netherlands [2,3] and Norway [4] since 1999, and in Spain [5] and 
England [6,7] thereafter, through a national cascade screening program for $\mathrm{FH}$ and has been evaluated as cost-effective [1].

The current study aims to evaluate the feasibility and associated cost of a nurse-led cascade screening of the relatives of the index patients (IP) using only phenotypic clinical criteria.

\section{Methods}

\section{Design}

Each Investigator included consecutive patients (called "Index Patient" or IP) who had baseline LDLC > $250 \mathrm{mg} / \mathrm{dl}$ or LDL-C > $190 \mathrm{mg} / \mathrm{dl}$ plus one of the following criteria: personal or family history of premature cardiovascular disease (CVD), tendon xanthoma, corneal arcus before 45 years or children with elevated cholesterol. Only those who had DLCN score 6 and signed a written consent were included. In currently treated individuals in whom there was no record of baseline LDL-C level, it was calculated by multiplying the current treated level with a correction factor depending of the current treatment according to Haralambos et al.[7] and assuming normal compliance (For treatment with antiPCSK9 monoclonal antibodies and with red rice yeast not mentioned in this paper, the correction factor was respectively 2,7 and 1,3 )

The inclusion of new $\mathrm{FH}$ patients (prospective) was encouraged but previously identified $\mathrm{FH}$ patients (retrospective) could also be enrolled in the study. The time for recruitment of index patients (IP) and relatives was expected to be approximately 3 months and 6 months respectively. Based on the prevalence data and, especially on the EuroAspire data [8], it was indeed expected that the prevalence of $\mathrm{FH}$ in patients admitted in coronary care units (CCU) outmatches more than 10 times the frequency observed in the general population (1/300).

When IPs had consented to participate in the study, nurses contacted each IP to draw a genealogic tree of his/her relatives and to collect the answers of satisfac- tion/anxiety questionnaire. The IP was asked to con- tact his relatives, to explain the $\mathrm{FH}$ cascade screening project and to ask their permission to be contacted by the nurse in a next stage. The nurses contacted only the relatives agreeing to be contacted, obtained a signed informed consent, sampled blood for lipid pro- file measurement (if the existing lipid profile was older than 6 months, didn't contain all required parameters or was obtained within 4 weeks after an ACS) and col- lected relevant clinical data The nurses also recorded answers to various questionnaires examining their awareness of FH in the family and of their own choles- terol level. For both IP and relatives, the nurses recorded the time spent at interviews and the travel distance as part of the measure of cost of this proced- ure. After the visit by the nurse, one of the three Steering Committee members (O.S.D; E.R; J.D.S.) sent a letter to the relatives encouraging them to consult their GP and a letter to the GP with the conclusion of the diagnosis as well as counselling on the treatment. A few weeks later, the relative was again contacted by phone by the nurse to answer a questionnaire examin- ing his/her anxiety towards the disease, and satisfac-tion about having participated in this project. The study was approved by the ethical committee of University Hospital of Gent.

\section{Predesigned diagnosis procedure for $\mathrm{FH}$}

Because in Belgium, only physicians are allowed to prescribe a genetic test, it was not possible to perform genetic testing in the relatives within the design of our study. The diagnosis of $\mathrm{FH}$ in relatives was thus based only on clinical and biological data using the DLCN criteria [1] as well as the age-specific LDL-C diagnostic cut-offs of the MEDPED FH criteria [9]. As previously published [10], the MEDPED FH criteria can be readily used in Belgium as the distribution of LDL-C levels in the general Belgian population $(131 \pm 34 \mathrm{mg} / \mathrm{dl})$ [11] is almost identical to that of the general US population $(130 \pm 31 \mathrm{mg} / \mathrm{dl})$. We considered various categories of likelihood of $\mathrm{FH}$ amongst the rel- atives: those with DLCN above 8 (DLCN definite FH), those with DLCN 6 and 8 (DLCN probable FH), those with positive MEDPED FH criteria (MEDPED probable $\mathrm{FH}$ ) whereas the remaining with DLCN $<6$ were considered to have no $\mathrm{FH}$.

\section{Establishment of rapid rule-out criteria for $\mathrm{FH}$}

In a post-hoc analysis, we attempted to establish more specific LDL-C diagnostic cut-offs than those of the classical MEDPED FH of Roger William et al.[9]. Recently, Brian Starr et al.[12] published age and gender-specific LDL-C diagnostic cut-offs which are based on the same principles than the classical MEDPED FH criteria but give more balanced specificity and sensitivity (significantly higher). To adjust for the difference in mean LDL-C levels between the population of the Netherlands and Belgium, we refered to different sets of published epidemiological data of LDL-C values (median) in the Belgian cohort of the the Asklepios Study [11] and in the Netherlands [10,13] (Supplementary Table 1). These 
"BEL-MEDPED FH cutoffs" were applied to the first rela- tives in a cascade screening manner: we applied it first to the first-degree relatives of the IP, and thereafter to the first-degree relatives of the "affected" first-degree relatives and so on.

\section{Results}

Rate of success in recruiting index patients

A total of 149 index patients (IP) were screened by 20 investigators from 15 centres of which 22 were consid- ered as screen failures (Figure 1). From the total of

127 IP included in the study, $118(92.9 \%)$ were seen at home by the nurses, while 9 patients could not be seen due to their unavailability.

Characteristics of the index patients

Of the 127 IP, $90(71 \%)$ had a definite FH and 37 (29\%) had a probable FH according to the DCLN score (Table 1 and Figure 1). Twenty-eight percent were "de novo" diagnoses. These patients were diagnosed for $\mathrm{FH}$ on average at the age of 35.6 years mostly during a routine check-up (54\%) or at the occurrence of a CVD event $(31 \%)$. Among the DLCN characteristics, tendon xanthomas and arcus cornealis (before age 45 years) were reported in $21 \%$ and $3 \%$ respectively.

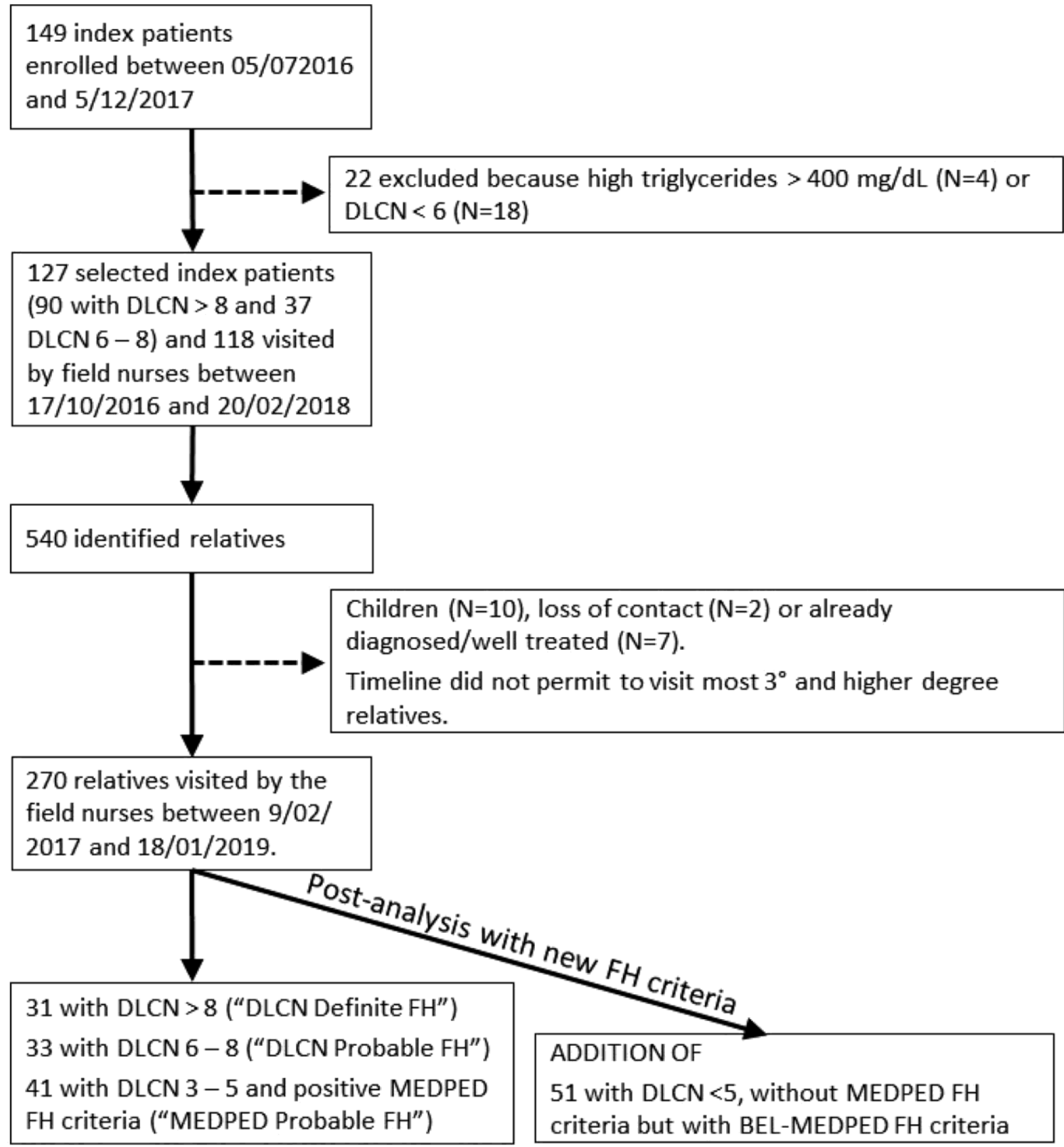

Figure 1. Algorithm and time scale of the Bel-Cascade study from IP selection to FH identification in relatives. 
Table 1. Characteristics of the index patients.

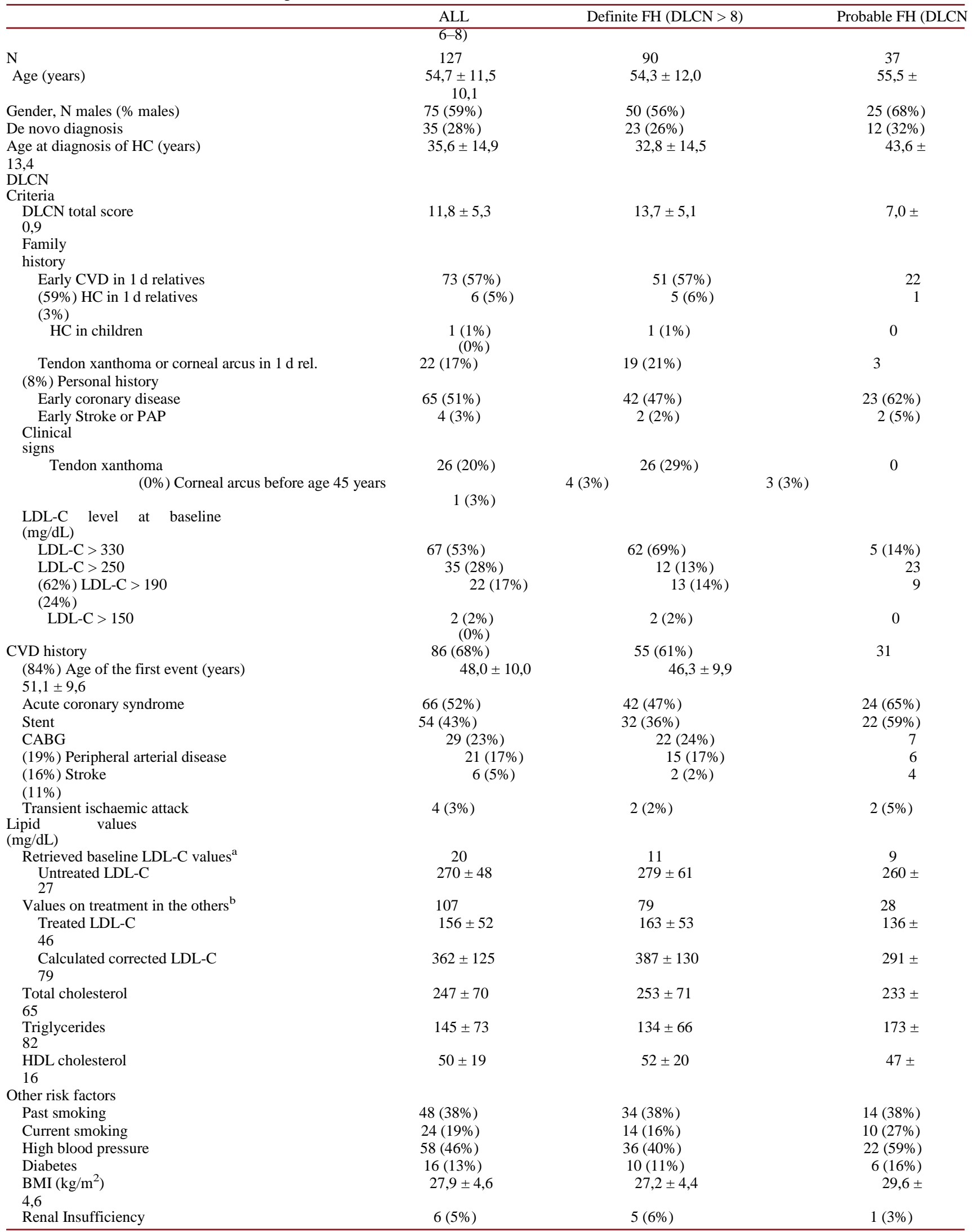

HC: hypercholesterolaemia; $1 \mathrm{~d}$ relatives: first-degree relatives; PAP: peripheral artery disease; CVD: cardiovascular disease.

${ }^{\mathrm{a}}$ It was possible to find the LDL-C levels before any treatment in 20 IP (11 definite DLCN FH and 9 probable DLCN

$\mathrm{FH})$.

${ }^{\mathrm{b}}$ The LDL-C on current treatment and calculated LDL-C (using Haralambos et al., see methodology) are given in those for whom we did not have the baseline LDL-C levels before treatment. 
Sixty-eight percent had a history of CV disease. Most (97\%) were treated at the moment of the recruitment: statin therapy in 127 out of 137, combined with ezetimibe (64 including 2 also with fibrate) or with antiPCSK 9 mAbs $\left(\mathrm{N}_{1 / 4} 2\right)$ or with ezetimibe and antiPCSK 9 mAbs ( $\mathrm{N}$ 1/4 12). 2 patients received antiPCSK9 mAbs alone.

Rate of success in visiting relatives and rate of $\mathrm{FH}$ diagnosis

540 relatives were identified by drawing the family tree of the IP (Figure 1). The timeline permitted to visit most of the first- and second-degree relatives but did not allow to visit all the identified higher degree relatives. Furthermore, some relatives whom nurses attempted to contact were excluded because they were too young $\left(\mathrm{N}^{1 / 4} 10\right)$, because errors in the contact information provided by the IP $\left(\mathrm{N}^{1 / 4} 2\right)$ or because the contacted relatives reported to be already diagnosed with FH and well treated (N 1/4 7).

Amongst these 270 relatives visited by the nurses, a total of 105 relatives had a definite FH with DLCN $>8(\mathrm{~N}$ $1 / 431$; "DLCN definite FH") or probable FH with DLCN 6-8 (N 1/4 33; "DLCN probable FH") or probable $\mathrm{FH}$ according to MEDPED criteria (N 1/4 41 "MEDPED 
Table 2. Characteristics of the relatives.

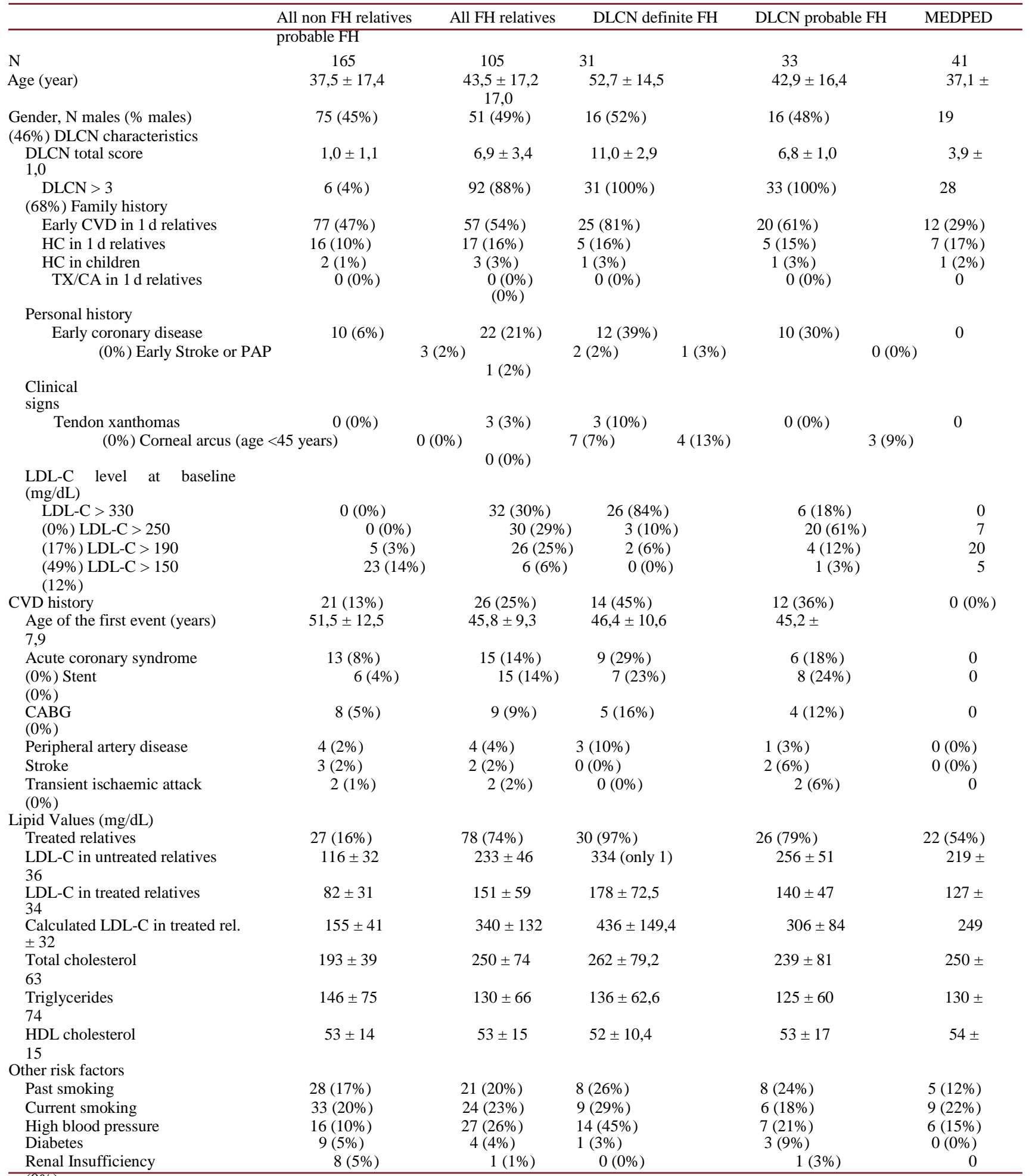

The "untreated" LDL-C levels are only the current levels of the untreated individuals whereas the "treated" LDL-C levels are the current levels of those who are treated. The other current lipid values are those currently observed whether or not the patients is currently treated. HC: hypercholesterolaemia; 1 d relatives: first-degree relatives; TX/CA: tendon xanthoma or corneal arcus (before 45 years); PAP: peripheral artery disease; CVD: cardiovascular disease.

probable FH") (Figure 1). Twenty-eight of these MEDPED probable FH relatives had their DLCN score between 3 and 5 (possible $\mathrm{FH}$ ). Amongst the remaining relatives, 6 had DLCN 3-5 (possible FH) and 159 had DLCN below 3 (no FH according to DLCN criteria), but we categorised all of these 162 as "non-FH" for the data presentation. The majority $(58 \%)$ of relatives had a first-degree relationship with the IP and $33 \%$ had a second-degree relationship. 
Characteristics of the relatives

Among the DLCN characteristics of the FH relatives, tendon xanthomas or corneal arcus were present in only a few (Table 2). The most common characteristic was a family history of CVD. Relatively more FH relatives $(74 \%)$ than non $\mathrm{FH}$ relatives $(16 \%)$ received lipid lowering treatment, with a proportion of treatment decreasing with the likelihood of a $\mathrm{FH}$ diagnosis $(97 \%$ if DLCN definite FH, 79\% if DLCN probable FH and $54 \%$ if MEDPED probable $\mathrm{FH}$ ) possibly due to lower baseline levels of LDL-C in those with the lower probability (as shown by the levels in those not treated).

Most of the relatives (92\% of FH relatives; $79 \%$ in non-FH relatives) claimed they had already performed blood testing for cholesterol levels (Supplementary Table 2. Question 1), but most FH (89\%) positive relatives remembered that cholesterol was high whereas only $41 \%$ non-FH relatives reported this (Question 4). 
Table 3. Answers to the satisfaction and anxiety questionnaires in the relatives.

\begin{tabular}{|c|c|c|c|c|c|}
\hline & Strongly agree & Partly agree & In doubt & Partly disagree & Strongly disagree \\
\hline \multicolumn{6}{|l|}{ A. Questions in FH relatives } \\
\hline 1. Having FH makes me anxious & $9 \%$ & $58 \%$ & $15 \%$ & $14 \%$ & $2 \%$ \\
\hline 2. I fear the future because of my high risk of CHD & $11 \%$ & $58 \%$ & $14 \%$ & $12 \%$ & $4 \%$ \\
\hline 3. Having FH makes me feel ill & - & $4 \%$ & $38 \%$ & $34 \%$ & $23 \%$ \\
\hline 4. I wish I didn't know I have FH & - & - & $30 \%$ & $46 \%$ & $23 \%$ \\
\hline 5. I'm satisfied to know I have FH & $25 \%$ & $1 \%$ & $45 \%$ & $29 \%$ & - \\
\hline 6. I believe my family should be screened for $\mathrm{FH}$ & $30 \%$ & $68 \%$ & - & $1 \%$ & - \\
\hline 7. I am satisfied I participated to this project & $37 \%$ & $63 \%$ & - & - & - \\
\hline 8. I wish I hadn't agreed to participate to this project & - & - & $2 \%$ & $77 \%$ & $21 \%$ \\
\hline \multicolumn{6}{|l|}{ B. Questions in non FH relatives } \\
\hline 1. I am relieved I don't have FH & $39 \%$ & $49 \%$ & $8 \%$ & $1 \%$ & $1 \%$ \\
\hline 2. I am satisfied I participated to this project & $51 \%$ & $48 \%$ & $1 \%$ & - & - \\
\hline 3. I wish I hadn't agreed to participate to this project & $0 \%$ & $1 \%$ & $3 \%$ & $56 \%$ & $41 \%$ \\
\hline 4. I believe my family should be screened for FH & $42 \%$ & $54 \%$ & $3 \%$ & $1 \%$ & - \\
\hline
\end{tabular}

A. Questions in FH relatives.

B. Questions in non FH relatives.

Follow-up contact, satisfaction and cost of the Cascade screening

Second contacts by phone were successful in 260 rela- tives (96.3\%). Amongst the $113 \mathrm{FH}$ relatives, the LLT was adjusted for only 16 patients (14\%) after visiting the GP: dose increase ( $\mathrm{N}^{1 / 4}$ 1), initiation of LLT ( $\mathrm{N}^{1 / 4}$ 5: 1 with PCSK9i, 2 with rosuvastatin, 2 with atorvastatin) or

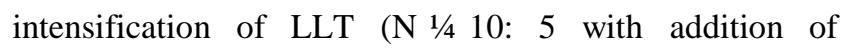
PCSK9i, 3 with ezetimibe, 2 with fenofibrate).

The travel distance and the time spent in the inter- view were respectively $101 \pm 53 \mathrm{~km}$ and $42 \pm 7,5 \mathrm{~min}$ for the IP; $95 \pm 55 \mathrm{~km}$ and $36 \pm 8 \mathrm{~min}$ for the relatives.

Based on the cost of the 2 nurses (50,000 euros/ year/nurse), the average travel distances $(0,3$ euros $/ \mathrm{km}$ for fuel cost) and the laboratory test (16 euros per standard lipid tests), we roughly estimate that it will cost 400 euros to either exclude or phenotypically confirm FH, which based on the proportion of relatives identified with FH translates into a cost of 1.000eper identified FH patient. This cost per identified FH patients is likely to be heavily inflated in the context of a clinical study and in the context of suboptimal resource utilisation in a first pilot study with steep learning curve.

$\mathrm{FH}$ relatives understand that $\mathrm{FH}$ is a risk situation (67\% expressed their anxiety about having FH and $69 \%$ their fear of coronary heart disease) but the majority (69\%) did not regret to have learned that they have $\mathrm{FH}$ and most of them (99\%) were satisfied to have participated to the cascade screening (Table

$3)$. On the other side, the non-FH relatives were also in a great majority (97\%) satisfied to have participated to this FH cascade screening project and were gener-ally relieved not to have FH.
Table 4. Age and gender-specific LDL-C diagnostic cutoffs adapted to Belgium to apply only to first degree relatives (by cascade screening).

\begin{tabular}{lcc}
\hline Age categories & Boys/men & Girls/women \\
\hline$<14$ years & 124 & 135 \\
15-24 years & 121 & 133 \\
$25-34$ years & 150 & 143 \\
35-44 years & 158 & 148 \\
45-54 years & 171 & 161 \\
$>55$ years & 169 & 173 \\
\hline
\end{tabular}

Post-hoc analysis of possible rule out criteria for $\mathrm{FH}$ in Belgian relatives of $\mathrm{FH}$ patients

Using the new set of criteria called "BEL-MEDPED FH cutoffs" (Table 4, see methods) we could suspect 51 more relatives (Figure 1). The characteristics of these relatives in terms of DLCN characteristics, CVD history and risk factors in comparison to those identified as having or not $\mathrm{FH}$ using the predesigned criteria are presented in Supplementary Table 3. These additional

$51 \mathrm{FH}$ relatives included the 6 relatives with DLCN between 3 and 5 (possible FH) not caught by the clas- sical MEDPED FH criteria. Their LDL-C were lower com- pared with the other FH groups (diagnosed by DLCN and classical MEDPED FH) but greater than in the non- FH group. In this group of relatives diagnosed for FH by the "BEL-MEDPED FH cutoffs", the prevalence of CVD, the age of occurrence of CVD and the prevalence of risk factors were however similar to those of the nonFH groups.

\section{Conclusions}

In a period of 18 months, our 2 nurses who collaborated with 20 investigators from 15 centres 
(specialized in cardiology and endocrinology) could examine 270 relatives of 118 index patients diagnosed for $\mathrm{FH}$, which allowed, by phenotyping, to suspect $\mathrm{FH}$ in 105 of these relatives $(39 \%)$.

With this pilot project we almost doubled the number of diagnosed FH patients, which is likely to be truncated because we limited our approach to those of at least 18 years old. We found also that most of the $\mathrm{FH}$ relatives were already treated and had a level of LDL-C that was quite similar to the LDL-C level in the treated index patient. Whilst this is reassuring as it mitigates the individ- ual risk of these $\mathrm{FH}$ relatives, it does not address the necessity of identifying these individuals as having $\mathrm{FH}$ given the resulting impact of this heritable disease on their relatives and offspring. Furthermore, LDL-C target attainment was suboptimal both in IP and their treated relatives and most relatives diagnosed with $\mathrm{FH}$ and treated were above 54 years of age. This calls for the necessity to identify FH and start LLT as early as possible in life.

After the study, it was clear that the number of relatives diagnosed with $\mathrm{FH}$ was lower than anticipated. One of the reasons is that DLCN > 5 is often difficult to reach without a positive genetic test. As a matter of fact, the DLCN cut-offs, as well as the classical MEDPED FH cut-offs of Roger Williams et al. [9] are designed to achieve high specificity, but at the detriment of sensitiv- ity. The age and gender-specific LDL-C diagnostic cut-offs published by Brian Starr et al [12) give a more balanced specificity and sensitivity than the MEDPED FH cut-off. Therefore, they are more appropriate for the purpose of cascade testing in the absence of a genetic diagnosis. We calibrated these cutoffs published by Brian Starr et al. based on the normal distribution of LDL-C in the 2 populations (the Dutch and Belgian). Doing this we found 51 more relatives suspected of FH. Their mean LDL-C was $151 \mathrm{mg} / \mathrm{dl}$ for those not treated, which was the case in $91 \%$. If labelled as $\mathrm{FH}$ these patients should receive lipid lowering treatment. Overall the BEL-MEDPED FH cut-offs allow to quickly rule out, using one single LDL-C criterion, $\mathrm{FH}$ in $42 \%(114 / 270)$ of the relatives and to suspect $\mathrm{FH}$ in $58 \%$ of the relatives (156/270). This simple strategy is ideal for broad scale nurse-led implementation of the detection of FH. It can be easily carried out by a nurse (a simple blood sample is suffi-cient) and in case of suspicion it can be followed by the search for other diagnostic criteria (those of the DLCN score) with the help of a general practitioner, who can refer the patient to a FH specialist who in turn can confirm the diagnosis.

The present study has some limitations. The first limitation is that, as contrary as planned, it was not possible to examine the cost and expected benefit resulting from the initiation or uptitration/intensification of lipid lowering treatment following the diagnosis. Not many relatives had a change in LLT after being informed about their FH status. These suboptimal results can be explained by the following reasons: the time between the visit to the GP and the second nurse contact by phone was probably too short to see a meaningful change in medication and, furthermore, most of FH relatives were already treated (and for those treated, their LDL cholesterol were similar to those of the IP followed by our investigators). The second limitation is that, for $16 \%$ (27 out of the 165) of the non FH relatives and in $74 \%$ (78 out of the 105) of the FH relatives, we did not have the baseline LDL-cholesterol level before treat-ment. Therefore, we estimated its value based on the current on-treatment LDL-C levels using coefficients that have been published [7] and that are related to the type and dosage of the current lipid lowering drug ther- apy. Such imputation methods may be used at the group level but may be inaccurate to estimate the pre-treatment LDL-C concentration at the level of the indi-vidual patient given the variable adherence to treat- ment and the variability of response to lipid lowering drug [14]. The third limitation is that, contrarily to other previous studies on cascade screening, we did not use genetic testing. Genetic testing allows to obtain unam-biguous diagnosis of FH, something which cannot be accomplished by clinical criteria. This does not devaluate our strategy in term of screening as we may consider it as a first step to raise awareness of the possibility of $\mathrm{FH}$ amongst the relatives and their doctors.

Our experience with this cascade screening strategy has also highlighted the two following problems that we did not anticipate.

The first was the slow recruitment of the IP, and thereby, the small proportion of newly diagnosed $\mathrm{FH}$ amongst them. Although investigators were recommended to enrol primarily newly diagnosed IP to allow exploration of families who had not been subjected to previous screening or at least who were not aware of $\mathrm{FH}$, the majority of IP were in fact patients in whom FH was already diagnosed decades ago. Based on the prevalence data and especially on the EuroAspire data [8] applicable to the setting in which we conducted the study, we expected a far more rapid recruitment of IP, which in reality took much longer and necessitated the extension of the recruitment period from 3 to 12 months. This calls for a design with a far broader range of entry points to enhance the efficacy of recruitment, i.e. screening of medical records, automatic alerts from labs, all directing the treating physician and the patient to a central contact point. This strategy would 
also allow to diagnose $\mathrm{FH}$ patients much earlier in the disease process. The entry point in this study was now patients visiting cardiologists and endocrinologists and therefore more likely to be already clinically affected.

The second problem was the low rate of FH diagnosis in relatives. In an approach based on cascade screening of first-degree relatives, we should expect a proportion of $\mathrm{FH}$ relatives of around 50\%. Previous experience in the Netherlands found a proportion of 8 FH positive patients out of the 20 relatives for each index patient in quite extended families [2]. We focussed our research of $\mathrm{FH}$ on more nuclear families using a cascade screening process (only screening first degree relatives of confirmed FH patients) in the absence of genetic analyses. Our low rate of $\mathrm{FH}$ amongst relatives may be the result of phenotypic diagnostic criteria that were highly specific but not sensitive enough (DLCN $>5$ or 8 and MEDPED FH cri- teria), perhaps not well adapted to the Belgian population. This could be improved by using more sensitive biological criteria calibrated for Belgium (see above) or by using a strategy including genetic testing and gen- etic counselling methods.

In conclusion, in a country where no national $\mathrm{FH}$ screening program exists, our pilot project, implementing a simple phenotypical FH cascade screening strategy using the collaboration of motivated specialists and of two nurses, has allowed to diagnose FH in 127 IP and 105 of their relatives over the two-year period of this pilot. The new" FH BEL-MEDPED cutoffs", which can be easily carried out by a nurse with a single blood sample will allow to further improve the sensitivity of detecting $\mathrm{FH}$ within families. Given the estimated number of 25,000 FH patients in Belgium, we can envision that national application of this strategy, which has proven highly successful in a number of countries, will require the sustained and extended collaboration of all stakeholders in order to achieve a nearly complete identification of suspected FH patients in a reasonable period of 10 years.

\section{Acknowledgments}

We thank the nurses as well as the index patients who participate to this study and collaborate by their effort in recruiting the relatives. We also thank doctors Ides Colin and Pascal Godart for participating to this study.

\section{Disclosure statement}

The authors have received lecture honoraria, consultancy fees and/or research funding from Actelion (J.D.S., A.B., I.E.), Amgen (O.S.D., E.R.R., A.M., I.B., H.V., G.M., S.C., J-P.L., I.E.), Astra Zeneca (O.S.D., A.M., I.B., H.V., F.C., F.L., G.M., S.C.,
I.E.), Bayer (A.B., I.E.), Boehringer Ingelheim (E.R.R., A.M., I.B., H.V., F.L., G.M., A.B., J-P.L., I.E.), Boston Scientific (S.C.), Bristol- Myers Squibb (J-P.L.), Daiichi-Sankyo (I.B.), Danone (O.S.D., J-P.L.), Eurogenerics (O.S.D.), Fresenius Medical Care (O.S.D.), Eli Lilly (A.M., F.L.), Johnson \& Johnson (A.M.), Merck Sharp \& Dome (O.S.D., E.R.R., A.M., J.D.S., F.L., M.G.), Menarini (J-P.L., I.E.), Mundi Pharma (F.L.), Mylan (O.S.D.), Novartis (E.R.R., A.M., I.B., A.F., H.V., F.C., G.M., P.V.), Novo-Nordisk (E.R.R., A.M., I.B., F.L.), Sandoz (I.B.) Sanofi-Aventis/Regeneron (O.S.D., E.R.R., J.D.S., A.M., I.B., H.V., F.L., G.M., S.C., A.B., J-P.L., I.E., M.G.), Servier (O.S.D., J-P.L., I.E.), Teva (E.R.R.).

\section{Funding}

The study was approved by the "Commissie voor Medische Ethiek" (UZP074) from the UZ Gent (University Hospital Ghent), approval number B670201628211. The study was also sponsored by SANOFI.

\section{References}

[1] Nordestgaard BG, Chapman MJ, Humphries SE, for the European Atherosclerosis Society Consensus Panel, et al. Familial hypercholesterolaemia is under-diagnosed and undertreated in the general popula- tion: guidance for clinicians to prevent coronary heart disease: Consensus Statement of the European Atherosclerosis Society. Eur Heart J. 2013;34(45): 3478-3490.

[2] Umans-Eckenhausen MA, Defesche JC, Sijbrands EJ, et al. Review of first 5 years of screening for familial hypercholesterolaemia in the Netherlands. Lancet. 2001;357(9251):165-168.

[3] Besseling J, Sjouke B, Kastelein JJ. Screening and treatment of familial hypercholesterolemia - Lessons from the past and opportunities for the future (based on the Anitschkow Lecture 2014). Atherosclerosis. 2015;241(2):597-606.

[4] Leren TP. Cascade genetic screening for familial hypercholesterolemia. Clin Genet. 2004;66(6):483-487.

[5] Rubio-Mar in P, Mich an-Don a A, Maraver-Delgado J, et al. Cascade screening program for familial 
hypercholesterolemia. Endocrinol Diabetes Nutr. 2018; 65(5):280-286.

[6] Crosland P, Maconachie R, Buckner S, et al. Cost-utility analysis of searching electronic health records and cascade testing to identify and diagnose familial hypercholesterolaemia in England and Wales. Atherosclerosis. 2018;275:80-87.

[7] Haralambos K, Whatley SD, Edwards R, et al. Clinical experience of scoring criteria for Familial Hypercholesterolaemia (FH) genetic testing in Wales. Atherosclerosis. 2015;240(1):190-196.

[8] De Backer G, Besseling J, Chapman J, et al. Prevalence and management of familial hypercholesterolaemia in coronary patients: an analysis of EUROASPIRE IV, a study of the European Society of Cardiology. Atherosclerosis. 2015;241(1):169-175.

[9] Williams RR, Hunt SC, Schumacher MC, et al.

Diagnosing heterozygous familial hypercholesterolemia using new practical criteria validated by molecu-

lar genetics. Am J Cardiol. 1993;72(2):171-176.

[10] Descamps OS, Van Caenegem O, Hermans MP, Belgian Atherosclerosis Society/Belgian Lipid Club (BAS/BLC), the Belgian Society of Cardiology (BSC) and the Royal Belgian Society of Laboratory Medicine (RBSLM), et al. A Belgian consensus strategy to iden-tify familial hypercholesterolaemia in the coronary care unit and its subsequent cascade screening and treatment: BEL-FaHST (The BELgium Familial Hypercholesterolaemia STrategy). Atherosclerosis. 2018;277:369-376.

[11] Rietzschel ER, De Buyzere ML, Bekaert S, Asklepios Investigators, et al. Rationale, design, methods and baseline characteristics of the Asklepios Study. Eur J Cardiovasc Prev Rehabil. 2007;14(2):179-191.

[12] Starr B, Hadfield SG, Hutten BA, et al. Development of

sensitive and specific age- and gender-specific lowdensity lipoprotein cholesterol cutoffs for diagnosis of first-degree relatives with familial hypercholesterolaemia in cascade testing. Clin Chem Lab Med. 2008;46(6): 791-803.

[13] Balder JW, de Vries JK, Nolte IM, et al. Lipid and lipoprotein reference values from 133,450 Dutch Lifelines participants: Age- and gender-specific baseline lipid values and percentiles. J Clin Lipidol. 2017;11(4):1055-1064.

[14] De Bacquer D, De Smedt D, Reiner Z, et al. Percentage low-density lipoprotein-cholesterol response to a given statin dose is not fixed across the pretreatment range: Real world evidence from clin- ical practice: Data from the ESC-EORP EUROASPIRE V Study. Eur J Prev Cardiolog. 2019;204748731987489. DOI:10.1177/2047487319874898 